\title{
ATUACÃO E DESENVOLVIMENTO PROFISSIONAL EM EDUCAÇÃO FÍSICA ADAPTADA DE ALUNOS EGRESSOS DO CURSO DE LICENCIATURA DA UNIVERSIDADE FEDERAL DE SANTA CATARINA
}

DOI: 105902/0102830819047

Data de envio: 07/08/2015

Data de aceite: 20/10/2015

Giandra Anceski Bataglion

Universidade Federal de Santa Catarina giandra_@hotmail.com

Beatriz Dittrich Schmitt Universidade Federal de Santa Catarina beatriz_bds@hotmail.com

Angela Teresinha Zuchetto Universidade Federal de Santa Catarina angela.zuchetto@ufsc.br

John Peter Nasser

Universidade Federal de Santa Catarina peter.nasser@ufsc.br

RESUMO: O objetivo foi analisar as experiências vivenciadas por sete alunos egressos da Universidade Federal de Santa Catarina que atuaram como bolsistas (extensão, monitoria, iniciação científica) do Programa de Atividade Motora Adaptada, considerando os ciclos de desenvolvimento da carreira docente. Para coleta dos dados, utilizou-se entrevista com roteiro semiestruturado. Os participantes se classificaram nos seguintes ciclos de desenvolvimento profissional: entrada na carreira, consolidação das competências profissionais na carreira e afirmação e diversificação na carreira. $\mathrm{Na}$ atuação profissional, constatou-se permanecia, abandono temporário e desistência na área de Educação Física Adaptada. Observou-se que o AMA influenciou a atuação docente dos participantes.

Palavras-chave: Educação continuada. Professor. Educação Física. 


\section{INTRODUÇÃO}

As universidades públicas brasileiras se fundamentam no princípio da indissociabilidade entre três domínios (ensino, pesquisa e extensão), de acordo com a Constituição Federal da República Federativa do Brasil (BRASIL, 2015). Quando as instituições conseguem articular essa tríade, pode-se promover transformações significativas no processo de ensino aprendizagem dos alunos, pois proporciona o ensino com suporte teórico e as pesquisas aprimoram os alicerces teóricos e possibilitam aproximar a comunidade da instituição universitária; ou seja, contribui para qualidade da formação inicial dos alunos.

O projeto pedagógico das universidades prevê atividades acadêmicas no decorrer da formação inicial que objetivam a aprendizagem a partir do trabalho docente (AFONSO; NORCCHI; OST, 2012). Para Hunger e colaboradores (2012), teoria e prática devem caminhar paralelamente neste processo, de forma a se complementarem. Para a autora, é durante os momentos de prática - os quais são poucos - que os estudantes podem vivenciar, diretamente, a profissão docente. Nesse sentido, os cursos de formação de professores os deixam mais preparados e qualificados para exercer a docência (FARIAS; NASCIMENTO, 2012).

Os serviços de extensão universitária se originaram em universidades inglesas e americanas a partir de cursos de educação continuada com a população adulta e abrangiam áreas rurais e urbanas (NOGUEIRA, 2001). No Brasil, as primeiras instituições denominadas universidades surgiram no Rio de Janeiro, em 1920; Minas Gerais, em 1927; e São Paulo, em 1934 (SOUSA, 2010). Inicialmente, a extensão universitária não era reconhecida como elemento indissociável à universidade brasileira e, em 1931, tem-se o primeiro registro de extensão universitária a partir do Decreto de Lei no 19.851 (NOGUEIRA, 2001; TAVARES et al., 2007).

A Universidade Federal de Santa Catarina (UFSC), localizada em Florianópolis/ Brasil, foi fundada em 1960, com o objetivo de promover o ensino, a pesquisa e a extensão (UFSC, 2015). Especificamente, o Programa de Atividade Motora 
Adaptada (AMA) é oferecido pelo Departamento de Educação Física do Centro de Desportos da UFSC, gratuitamente, desde 1995. O objetivo do programa se relaciona à tríade: ensino-pesquisa-extensão. Assim, oferece atividades motoras adaptadas a pessoas com deficiências (extensão), oportuniza vivências práticas aos graduandos do curso de Educação Física (ensino/formação) e desenvolve estudos nessa área (pesquisa) (ZUCHETTO, 2008; ZUCHETTO; FRANÇA; NASSER, 2011; SCHMITT; ZUCHETTO, 2012; BATAGLION; ZUCHETTO, 2014; BATAGLION; ZUCHETTO; NASSER, 2014; SCHMITT; ZUCHETTO, 2014).

O AMA atende a necessidade da disciplina denominada Educação Física Adaptada. Os acadêmicos matriculados nessa disciplina cumprem 18 horas/ aula de atividades de Prática Pedagógica como Componente Curricular (PPCC) no programa AMA. Essa vivência oportuniza aos acadêmicos a vinculação dos conteúdos teóricos diretamente às diferentes realidades que os cercam na prática docente (SCHMITT; ZUCHETTO, 2012). No que se refere às tarefas desempenhadas pelos bolsistas, elas variam entre auxiliar, planejar e ministrar aulas para os alunos do programa até a organização de materiais didáticos e a atuação como monitores da disciplina. Além disso, a depender do tipo de bolsa que o aluno possui e de seu interesse, o bolsista participa das pesquisas realizadas no laboratório, o que caracteriza a iniciação científica na área. A professora da disciplina e coordenadora do programa supervisiona e orienta todas as atividades do bolsista (ZUCHETTO, 2008). Para Petrica e Serrano (2015), esse modelo de preparação para a prática é caracterizado por ser um ensino partilhado por mais de um professor em formação (acadêmicos) e por mais do que um responsável (professor, estagiários e monitores da disciplina), aos seus pares (colegas) ou com alunos reais que no contexto do AMA são os alunos com deficiência.

É válido acrescentar que Atividade Motora Adaptada é um programa individualizado - elaborado por profissionais qualificados a fim de suprir as necessidades especiais dos indivíduos com deficiência - que visam aumentar a meta de atividade física de pessoas com limitação de movimento e/ou restrições 
sociais por meio de dança, jogos, esportes e brincadeiras (SHERRIL, 2004; WINNICK, 2011). Neste contexto, o termo adaptada diz respeito às adequações quanto às formas de ensino, tais quais, a disponibilização de apoio e/ou comandos físico, verbal, visual e ao uso e ajustes nos materiais, no ambiente, nos objetivos e nos métodos.

Após a conclusão da graduação, os alunos egressos lançam-se no mercado de trabalho e iniciam a carreira docente que, por sua vez, pode ser compreendida analisando-se as características dos ciclos de desenvolvimento profissional de Educação Física (FARIAS, 2010). A autora salienta que a carreira docente pode ser dividida em cinco etapas: Entrada na carreira (1 a 4 anos de docência); Consolidação das competências profissionais na carreira docente (5 a 9 anos de docência); Afirmação e diversificação na carreira (10 a 19 anos de docência); Renovação da carreira (20 a 27 anos de docência); Maturidade na carreira (28 a 38 anos de docência). Vale destacar que "a divisão dos ciclos em anos não significa que existam rompimentos, e sim, a existência de zonas de transição entre um ciclo e outro" (FARIAS; NASCIMENTO, 2012).

Ressalte-se que assuntos relacionados à importância da Atividade Motora Adaptada são frequentemente apresentados na literatura, sobretudo no que tange às discussões sobre os benefícios proporcionados pela Atividade Motora Adaptada com o intuito de suprir as necessidades especiais ligadas à educação física e ao esporte (WINNICK, 2011). Por outro lado, na literatura pesquisada, observaramse lacunas na produção científica de pesquisas que utilizam o embasamento teórico dos ciclos de desenvolvimento profissional na carreira docente associada à subárea de Educação Física Adaptada. À luz dessas ideias, essa pesquisa pretende contribuir com a produção de conhecimento científico e encorajar o desenvolvimento de outros estudos sobre essa temática.

Com base nessas considerações, o objetivo desse estudo é analisar as experiências vivenciadas por alunos egressos da UFSC, que atuaram como bolsistas do Programa de Atividade Motora Adaptada, considerando os ciclos 
de desenvolvimento da carreira docente. Entende-se que ao caracterizar os participantes de acordo com o ano de conclusão da formação inicial é possível identificar o ciclo de desenvolvimento profissional em que se encontram e, na mesma medida, identificar fatos marcantes, relacionados com Educação Física Adaptada, que vivenciaram durante a sua atuação docente.

\section{METODOLOGIA}

\subsection{Tipo de estudo}

Esse estudo foi realizado por meio de investigação descritiva com abordagem qualitativa. De acordo com Gonsalves (2007), a pesquisa descritiva intenta observar determinada população ou fenômeno a fim de estabelecer relações entre as variáveis, relatar e comparar informações. Para essa autora, a pesquisa qualitativa, por si só, é descritiva e possibilita que os dados sejam analisados de forma indutiva por meio da interpretação dos fenômenos.

\subsection{Participantes}

Participaram da pesquisa sete alunos egressos do curso de Licenciatura em Educação Física da Universidade Federal de Santa Catarina, da quais seis do sexo feminino e um do sexo masculino. Os critérios de inclusão foram: participantes que tivessem atuado como bolsistas em funções distintas (extensão, monitoria, iniciação científica) no programa de Atividade Motora Adaptada por, pelo menos, dois anos consecutivos no período compreendido entre 1997 a 2013.

\subsection{Instrumentos para coleta dos dados}

O instrumento utilizado na presente pesquisa foi entrevista com roteiro semiestruturado com 10 perguntas abertas e fechadas que contemplaram as seguintes dimensões: características da formação inicial (curso, ano de conclusão, caracterização do engajamento em ensino-pesquisa-extensão), características profissionais (ciclo de desenvolvimento, área de atuação) e características pessoais 
(dificuldades e desafios enfrentados durante a carreira docente). Esse instrumento foi construído especialmente para essa pesquisa.

Posteriormente, para a análise dos ciclos de desenvolvimento profissional, foi utilizado o modelo desenvolvido por Farias (2010), o qual classifica os ciclos em:

a) Entrada (1 a 4 anos de docência): é o primeiro contato com a profissão, quando se está ainda na formação inicial. Este ciclo se caracteriza pelo choque com a realidade, onde ocorre o enfrentamento de situações adversas no âmbito das competências profissionais. Pode ocorrer desânimo e vontade de desistir da profissão;

b) Consolidação das competências profissionais na carreira (5 a 9 anos de docência): aqui, os professores passam a buscar informações em outras fontes de conhecimento e até mesmo a participar de programas de formação continuada para adquirir competências profissionais que os permitam aprimorar a sua prática docente. Com isso, passam a se sentir mais valorizados e almejam continuar na carreira com planos futuros;

c) Afirmação e diversificação na carreira (10 a 19 anos de docência): este é o ciclo de reconhecimento profissional decorrente da titulação e do status profissional. Já se tem domínio dos trabalhos de rotina e uma relação de companheirismo e/ou parceria com os colegas de trabalho. Surgem novas expectativas e é comum os professores de Educação Física assumirem cargos administrativos neste ciclo. Há também a efetivação das metacompetências e transcompetências;

d) Renovação na carreira (20 a 27 anos de docência): o tempo de experiência permite que o professor tenha domínio das atividades de rotina na escola. Surge aqui a expectativa pela aposentadoria, mas também há quem prefira continuar suas atividades docentes mesmo apto a se aposentar. Por isso, pode-se dizer que nesse ciclo existem três caracterizações para os professores, isto é: os encantados com a docência, os defensores da causa docente e os renovadores da atuação profissional; 
e) Maturidade na carreira (28 a 38 anos de docência): todas as vivências de anos de carreira estão concentradas nesse ciclo, isto evidencia a consolidação do conhecimento tácito. A busca por novos conhecimentos se torna cada vez menos importante e surge o sentimento de realização profissional. Há professores que se tornam amargos e passam a reclamar diariamente dos problemas da profissão.

\subsection{Procedimentos para coleta dos dados}

A coleta de dados foi realizada após aprovação do projeto no Comitê de Ética em Pesquisa com Seres Humanos da Universidade Federal de Santa Catarina (Processo no 911/10). Todos os participantes assinaram o Termo de Consentimento Livre e Esclarecido.

Inicialmente, os participantes foram contatados e, ato contínuo, esclarecidos sobre os objetivos da pesquisa e convidados a dele participarem. As entrevistas foram realizadas de acordo com a disponibilidade de horário dos participantes em diferentes períodos do dia e locais de modo a favorecer a adesão. A partir das respostas das entrevistas, foram identificados os ciclos de desenvolvimento profissional em que os participantes se encontram.

\subsection{Análise dos dados}

Inicialmente, as entrevistas foram transcritas na íntegra de acordo com as orientações de Duarte (2004). Posteriormente, os dados foram tabulados em planilha eletrônica do programa Microsoft Excel® (versão 2010). Em seguida, os dados foram analisados a partir de recursos da estatística descritiva.

Por fim, as informações foram analisadas por meio da técnica de análise de conteúdo que emprega procedimentos sistemáticos e objetivos de descrição dos dados das mensagens, a partir da elaboração de categorias de análise (BARDIN, 2011). 


\section{RESULTADOS E DISCUSSÃO}

Desde 1995, período em que o AMA foi criado, os graduandos do curso de Educação Física têm a possibilidade de vivenciar o ensino, a pesquisa e a extensão em torno da área de Educação Física Adaptada. A partir do momento em que o acadêmico assume seu papel, seja de aluno ou de bolsista, passa a se engajar na tríade ensino-pesquisa-extensão, preconizada pela UFSC. Assim, é possível instigar a curiosidade do acadêmico a fim de que o mesmo tenha interesse em permanecer na área da Educação Física Adaptada.

Ao longo do período de existência do AMA, oito acadêmicos atuaram como bolsistas (extensão, monitoria e/ou iniciação científica) durante dois anos consecutivos, atendendo aos critérios de inclusão preestabelecidos. Dos oito indivíduos convidados a participar dessa pesquisa, sete aceitaram formalmente $o$ convite e um não participou porque não foi localizado. De acordo com os critérios de inclusão do presente estudo, nota-se que o universo foi equivalente a oito indivíduos. Apesar desse número ser numericamente reduzido, considerandose o período entre 1997 a 2014 (19 anos), deve-se reconhecer sua importância, uma vez que a amostra, composta por sete indivíduos, representa, de fato, o perfil dos acadêmicos que se engajam com a Universidade em suas diferentes dimensões, sobretudo na área de Atividade Motora Adaptada. Além disso, é inegável a possibilidade de que esses acadêmicos egressos foram e continuarão sendo agentes de mudança no cenário regional, nacional e mundial nessa área de atuação profissional que Ihes despertou interesse durante a formação inicial.

Os anos de conclusão do curso de graduação em Educação Física (Plena ou Licenciatura) dos participantes foram 1997, 2003, 2007, 2012 e 2013. Vale ressaltar que três dos participantes concluíram a graduação em 1997. Dessa forma, se enquadram em diferentes ciclos de desenvolvimento profissional, conforme apresentado na Tabela 1. 


\begin{tabular}{lc}
\hline Ciclos de desenvolvimento profissional & Participantes \\
\hline Entrada na carreira (1 a 4 anos de docência) & 2 \\
Consolidação das competências profissionais na & 1 \\
carreira (5 a 9 anos de docência) & \\
Afirmação e diversificação da carreira (10 a 19 anos & 4 \\
de docência) & 7 \\
Total & \\
\hline
\end{tabular}

Tabela 1 - Ciclos de desenvolvimento profissional dos participantes entrevistados.

Com base no exposto anteriormente, evidencia-se a relação existente entre o ano de conclusão do curso de graduação com os ciclos de desenvolvimento profissional. Afinal, de acordo com a classificação desenvolvida por Farias (2010), cada um dos ciclos se caracteriza por determinado período de carreira: entrada na carreira (1 a 4 anos de docência); consolidação das competências profissionais na carreira (5 a 9 anos de docência); afirmação e diversificação na carreira (10 a 19 anos de docência); renovação na carreira (20 a 27 anos de docência) e maturidade na carreira ( 28 a 38 anos de docência).

$\mathrm{Na}$ Tabela 1, nota-se que os participantes estão classificados em três ciclos de desenvolvimento profissional (entrada na carreira, consolidação das competências profissionais na carreira e afirmação e diversificação na carreira). Os ciclos de renovação na carreira (20 a 27 anos de docência) e maturidade na carreira (28 a 38 anos de docência) não foram contemplados em razão da data de criação do AMA, 1995, 19 anos atrás.

No que tange à titulação dos participantes, apresenta-se a Tabela 2. 


\begin{tabular}{lc}
\hline Titulação & Número de Participantes \\
\hline Graduação & 7 \\
Especialização & 3 \\
Mestrado & 4 \\
Especialização e Mestrado & 2 \\
\hline
\end{tabular}

Tabela 2 - Titulação dos participantes da pesquisa.

Quanto à área de atuação profissional, Educação Física Adaptada, cinco participantes permaneceram nesse campo de atuação. Dos dois entrevistados que abandonaram esse campo de atuação profissional, destaca-se que um informou mudança na escolha profissional (ingressou em outro curso de graduação) e o outro relatou que prestou serviços autônomos sem relação com a Educação Física, mas pretende retornar para a área porque almeja ingressar no curso de pósgraduação com a temática de Atividade Motora Adaptada. Dos três que possuem especialização, um encontra-se no ciclo de consolidação das competências profissionais na carreira e dois no ciclo de afirmação e diversificação da carreira. Enquanto que dos quatro que possuem mestrado, um se encontra no ciclo de consolidação das competências profissionais na carreira e três no ciclo de afirmação e diversificação da carreira.

Após o período de formação inicial, além de ingressarem em cursos de pós-graduação, os participantes passaram a atuar no campo docente (Escolas; Universidades; Associação de Pais e Amigos dos Excepcionais - APAES; Associação de Pais, Amigos e Pessoas com Deficiência, de Funcionários do Banco do Brasil e da Comunidade - APABB; Associação Catarinense de Esportes Adaptados ACESA; Instituto Psiquiátrico; Fundação Catarinense de Educação Especial) e/ou em clubes e academias ministrando aulas para pessoas com e sem deficiência. Um participante mencionou o desenvolvimento do trabalho como Personal Trainer para alunos com deficiência. Além disso, houve participação em cargos administrativos 
como na Coordenadoria Estadual de Educação, em direção e coordenação de escolas e atuações como professores auxiliares de Educação Especial.

Dois dos entrevistados, após a conclusão do curso de graduação (1997 e 2007), atuaram como docentes em escolas do sistema regular de ensino por curto período de tempo (inferior a 12 meses). Esses relataram a preferência por outros locais de trabalho em virtude de não se identificarem com o ambiente escolar. Salienta-se que o desencanto relatado no que tange à atuação docente no ensino regular, é comum no ciclo de entrada na carreira e justifica a não permanência na docência. Com isso os profissionais assumem atividades burocráticas ou até mesmo abandonam definitivamente a profissão (HUBERMAN, 1995). Nessas duas entrevistas isso foi observado, pois logo após a formação inicial foi quando ingressaram na carreira docente, mesmo período em que decretaram abandono dessa atuação ou que assumiram cargo na Coordenadoria de Estadual de Educação. Atualmente, em 2014, datam 17 e sete anos após a conclusão de suas graduações e ambos os indivíduos têm interesse em ingressar em um Programa de Pós-graduação Strictu Sensu, um deles visa o curso de Mestrado; e o outro de Doutorado. Vale acrescentar que o participante que almeja ingressar no Doutorado iniciou, também em 2014, a sua trajetória na carreira docente no ensino superior atuando na disciplina de Educação Física Adaptada.

Outros dois entrevistados que se formaram em 1997 e 2003, ingressaram no ambiente escolar logo após egressos e permanecem atuando até os dias atuais. Um deles trabalha em Cargo administrativo (direção de escola) na Rede Municipal de Ensino de Florianópolis, de acordo com o que sugere o ciclo de carreira docente no qual o mesmo está classificado (afirmação e diversificação na carreira). Esse docente também dá aulas de Educação Física para turmas de Ensino Fundamental e Infantil. O outro participante citado atuou na Educação Infantil até o ano de 2011 e, atualmente, é Professor Auxiliar de Educação Especial na Rede Municipal de Ensino e em duas Faculdades privadas de Educação Física no Estado de Santa Catarina, onde leciona disciplinas de Educação Física Adaptada. 
A opção pela carreira no ensino superior com ênfase em Educação Física Adaptada também foi evidenciada em outro participante, apesar de as atividades profissionais exercidas pelo entrevistado, após a formação inicial, não se restringirem a isso. Nesse sentido, pode-se citar a atuação docente em espaços para além do ensino regular. Um dos entrevistados informou a desistência da profissão, isto é, abandono da Educação Física Adaptada. A justificativa disto se deve ao elevado interesse pela área de Nutrição, manifestado desde os primeiros anos da graduação em Educação Física. É importante esclarecer que os demais entrevistados permaneceram na área da Educação Física, com especial atenção para a Educação Física Adaptada, tanto no campo de atuação (trabalho), quanto nos cursos de pós-graduação. Além disso, três participantes voltaram a se envolver com o AMA após a conclusão do(s) curso(s) de graduação e/ou pós-graduação.

Daqueles que relataram experiência docente em escolas de ensino regulares, três tiveram/têm a presença de alunos com deficiência e referiram que, apesar das dificuldades e limitações desses estudantes, nunca encontraram grandes problemas para planejar e ministrar as aulas, apenas a necessidade de adaptar algumas propostas para que ocorresse o engajamento do aluno na atividade. Nesse sentido, os três docentes ressaltaram que essa segurança é resultado do envolvimento e da trajetória no programa AMA que, por sua vez, deu suporte para trabalhar com pessoas com deficiência em diferentes contextos de ensino, possibilitando a compreensão dos seus limites e das diferenças individuais de qualquer aluno (com e sem deficiência).

Um desses três docentes explicou e exemplificou a sua experiência ao relatar que, logo após se formar, começou a trabalhar como professor de Educação Física e lecionou em uma turma do ensino infantil que possuía um aluno com deficiência física do tipo paralisia cerebral. O egresso disse que os anos de experiência no AMA e o consequente conhecimento sobre a deficiência (características, possibilidades e necessidades de adequações) facilitaram o trabalho com a criança e ressaltou: 
"Conversei com os responsáveis pela escola e comecei a buscar novos materiais, a propor atividades fora da sala e em grupo. Em quatro meses ele apresentou melhoras no desenvolvimento passando a falar algumas palavras como bola e gol e, a caminhar se segurando/apoiando nas paredes. Isso fez com que os familiares buscassem novas formas de tratamento como fisioterapia e fonoaudiologia" (Participante 3 consolidação das competências profissionais).

Ribeiro (2009) ressalta a importância de que o professor tenha as informações necessárias para reconhecer os interesses e as necessidades do aluno com deficiência, para então favorecer a sua participação nas aulas e potencializar as suas capacidades que repercutirão tanto no contexto escolar quanto extraescolar. Para tanto, é necessário que a escola apresente um currículo flexível e apoie a proposta de trabalho docente (RIBEIRO, 2009).

O conceito de currículo pode ser melhor compreendido a partir de Domingues (1986) como "um curso, uma sequencia de cursos numa escola ou universidade com finalidade de graduação; um conjunto total de cursos ensinados numa instituição educacional ou num departamento".

Uma das participantes da pesquisa, que está no ciclo de afirmação e diversificação na carreira e que, além de ter iniciado suas atividades profissionais na área de Educação Física adaptada no âmbito escolar logo após a formação inicial, atua como Professora Auxiliar de Educação Especial na rede regular de ensino, destacou a importância do envolvimento de toda a comunidade escolar e órgãos afins. Ademais, frisou sobre a necessidade da compreensão geral sobre as pessoas com deficiência (aspectos físicas, motores, orgânicos, emocionais, etc; suas capacidades e limitações) para que o ambiente escolar se tornasse realmente inclusivo:

"Desde que comecei a atuar em instituições de ensino, sempre tive uma busca incessante por tentar mostrar às pessoas a importância de valorizar e respeitar as diferenças dos alunos, tentando desmistificar a ideia de que existem espaços, atividades, metodologias e planejamentos específicos só para alunos com deficiência. Acredito que Escola Inclusiva é o mesmo que Escola de Qualidade, pois a partir do momento que nos preocupamos com cada detalhe para atingir a qualidade de ensino, se realmente tiver qualidade, será um ambiente inclusivo" (Participante 5 - afirmação e diversificação na carreira). 
As legislações sobre a educação especial sofreram alterações ao longo da implementação do AMA, o qual se modificou para cumprir as exigências normativas (ZUCHETTO, 2008) e para suprir as demandas necessárias, especialmente, no sentido das informações/conhecimentos acerca da Educação Física Inclusiva. Até mesmo porque esse movimento não se consolidará se não houver, além da formulação de leis, uma mobilização social para a construção de novos valores éticos e morais (RIBEIRO, 2009). Para tanto, a escola deve oferecer um ambiente menos restritivo a englobar não somente a estrutura física da escola, mas também o atendimento do professor, os recursos pedagógicos específicos, a proposta curricular, o projeto pedagógico da escola e o processo de avaliação (RIBEIRO, 2009). A autora ainda ressalta que um dos desafios é a elaboração de currículos diferenciados, com conteúdos e metodologias que favoreçam a inclusão, e menciona que os professores, por sua vez, para conseguirem avançar a nível prático, devem passar por um processo de intervenção durante a formação inicial e continuada de modo a serem preparados, orientados e atuarem como agentes facilitadores, participativos e conhecedores das necessidades e características de seus alunos.

No que se refere à participação como bolsistas do AMA, todos os participantes da pesquisa consideraram que as atividades realizadas e os conhecimentos adquiridos nesse período exerceram influência para decidirem por permanecer atuando profissionalmente na área de Educação Física Adaptada. Ressaltaram também, que tal influência é percebida diariamente em seus procedimentos e condutas de trabalho.

Foram apontados como fatores influentes, pelo AMA, para e na atuação profissional: descoberta/identificação com a área e desejo em nela permanecer; capacidade de transferir os conhecimentos adquiridos para a prática profissional; a experiência na área e o bom relacionamento com as pessoas (alunos, familiares e coordenadora do programa) ampliam oportunidades de trabalho; a possibilidade de utilização das estratégias de ensino, já sistematizadas no AMA, facilitam e dão segurança no trabalho diário; as atividades desenvolvidas, enquanto bolsistas de 
iniciação científica, serviram como estímulo para o ingresso em cursos de pósgraduação; a influência na vida diária (profissional e pessoal), aprendizado na relação criança-mãe, criança-adulto e criança-criança.

Ao analisar os relatos sobre os fatos marcantes na carreira dos participantes, verificaram-se relações entre os depoimentos e os ciclos de desenvolvimento profissional em que cada um se encontra. Foi possível observar em um mesmo ciclo a existência de profissionais com características distintas:

"Um fato marcante para mim foi o período de convivência e trabalho no projeto $\mathrm{AMA}$, onde me apeguei às crianças e ao tipo de trabalho realizado sentindo prazer em aprender sobre a área da educação física adaptada e onde iniciei o trabalho com crianças" (Participante 1 - entrada na carreira);

"O que me marcou foi que durante o curso já era possível verificar a dificuldade em atuar na área em relação à questão financeira e valorização da carreira, fatores que desmotivaram a atuação na área profissional da Educação Física" (Participante 2 - entrada na carreira).

Nota-se em uma participante o desejo em permanecer na docência e, na outra, o choque com a realidade, resultado semelhante ao encontrado por Farias (2010).

O participante que se encontra no ciclo de consolidação das competências profissionais, atualmente almeja o doutorado, e está em fase de diversificação das fontes de conhecimento:

"Foi marcante, pessoalmente por ser um sonho, morar fora do país e fazer, no mestrado, algo profissionalizante, descrever, pôr no papel e publicar o trabalho que eu desenvolvo no dia-a-dia. Foi mais um relato, uma construção teórica/escrita do trabalho que eu vinha realizando com os projetos de natação adaptada. Desde 2007 eu vinha pensando nisso, e no mestrado deu certo" (Participante 3 - consolidação das competências profissionais).

E para confirmar a inserção desse participante no referido ciclo, acrescenta-se narrativa que indica o momento caracterizado pela aquisição de competências profissionais:

"Poder vivenciar o trabalho que se gosta com as pessoas com deficiências é positivo (sair com alunos e praticar corrida, natação, envolver os pais, a sociedade... é uma conquista muito grande) e também há pontos 
negativos porque é um caminho árduo no qual o trabalho pode levar anos e anos para alcançar um resultado no aluno" (Participante 3 consolidação das competências profissionais).

Ainda se pode dizer que, conforme necessário, o participante se dispõe a alterar suas estratégias metodológicas:

"Trabalho abre portas para o trabalho e sempre surgem novos desafios seja no campo acadêmico, ou para atender novos alunos com novas deficiências e também para lidar com os seus responsáveis" (Participante 3 - consolidação das competências profissionais).

De acordo com a fala do participante 3, pode-se dizer que as vivências diárias durante a carreira (novas oportunidades, desafios, necessidades, aprendizagens) podem modificar as ações dos profissionais, tanto no ciclo atual quanto os subsequentes, o que ilustra, assim, suas características profissionais e pessoais (FARIAS et al., 2015). Por isso, de acordo com os autores, as características dos ciclos de desenvolvimento profissional, não são um retrato único para o profissional, muito embora sinalizem as possíveis particularidades que possam apresentar em cada uma dessas fases da carreira, com base em sua formação e nas experiências profissionais.

No ciclo de afirmação e diversificação da carreira, os participantes apresentaram como principal característica a partilha com os pares da Educação Física:

"É muito importante o vínculo que tenho com o Grupo de Pesquisa do AMA até os dias de hoje (e pretendo nunca perder esse vínculo). Esse vínculo me permite continuar pesquisando e produzir artigos com o grupo, apesar de que atualmente eu trabalho em outro estado em instituições privadas de ensino superior" (Participante 4 - afirmação e diversificação da carreira).

Além disso, mostraram-se satisfeitos quanto ao reconhecimento profissional na carreira:

"Durante todos os anos de docência, trabalhando com alunos com deficiência, sempre tive o respeito e a valorização da comunidade escolar e, principalmente, dos pais e/ou familiares dos alunos. E isto, sem dúvida, é o ponto mais positivo da carreira docente" (Participante 5 - afirmação e diversificação na carreira). 
Por fim, destaca-se a importância de valorizar as histórias e narrativas de professores, conforme sugerido por Santos, Bracht e Almeida (2009), que preconizam entrevistar professores e lhes permitir compartilhar experiências. Assim, essa pesquisa se justifica porque compreendeu a identidade desses profissionais, especificamente no contexto das contribuições da formação inicial para a vida profissional. Para Farias e Nascimento (2012), há lacunas na literatura brasileira no que se refere à identidade profissional com ênfase na intervenção e na formação, sobretudo utilizando ferramentas metodológicas que possibilitem a valorização dos professores.

Além disso, os ciclos de desenvolvimento profissional foram utilizados como artifício metodológico e, por essa razão, os resultados obtidos contemplaram peculiaridades desses ciclos. É sabido que essa metodologia, apesar de ter suas características estabelecidas, permite que o participante se encontre em períodos de transição entre um ciclo e outro. Nesses períodos há permutas entre as características dos ciclos que, por vezes, se entrelaçam. Nessa perspectiva, a carreira não pode ser interpretada como um desenvolvimento linear, pois significa um movimento para o profissional, bem como para a sua instituição de trabalho. A sequência dos ciclos durante a carreira contempla, pois, distintos caminhos e momentos de descontinuidades (FARIAS et al., 2015). No entanto, nesse trabalho não foram observados participantes nesse momento de transição, porquanto apresentaram características bem definidas e específicas de cada ciclo.

\section{CONCLUSÃO}

Pode-se concluir, a partir do presente estudo, que um programa de extensão universitária, em paralelo com o ensino e com a pesquisa, contribui positivamente não só na formação inicial de acadêmicos do curso de Educação Física, mas também na trajetória de suas carreiras profissionais, pois prima pela indissociabilidade ensino, pesquisa e extensão, conforme preconiza a lei.

As características dos entrevistados evidencia que o ano de conclusão da 
graduação foi distinto entre os participantes, mas que, desde a data de criação do AMA, foi frequente o interesse de acadêmicos/bolsistas na área da Educação Física Adaptada. A partir do ano de conclusão foi possível classificar os ciclos de desenvolvimento profissional. Os participantes apresentam diferentes titulações acadêmicas (graduação, especialização, mestrado e/ou doutorado) e atuações profissionais distintas (permanência - ensino regular, ensino superior ou atividades extracurriculares; abandono temporário - atividades administrativas burocráticas; e desistência da área - migração para área adjacente a Educação Física).

Sugerem-se mais pesquisas relacionadas a atuação e ao desenvolvimento profissional de professores que trabalham direta ou indiretamente com a Educação Física Adaptada, Esportes Adaptados ou, ainda, Educação Inclusão. Essas temáticas cada vez mais têm recebido atenção de pesquisadores e profissionais da área, no entanto, ainda há a necessidade do preenchimento de inúmeras lacunas existentes na literatura quanto a este assunto.

\section{REFERÊNCIAS}

AFONSO, M. R.; NOCCHI, N.; OST, M. A. A prática pedagógica como componente curricular: contextos e processos. In: NASCIMENTO, J. V.; FARIAS, G. O. (Orgs.). Construção da identidade profissional em Educação Física: da formação à intervenção. Florianópolis: Editora da UDESC, 2012. p. 61-79.

BARDIN, L. Análise de conteúdo. São Paulo: Edições 70, 229 p. 2011.

BATAGLION, G. A.; ZUCHETTO, A. T. Interpersonal Relations Evidenced in the Classes of Adapted Motor Activity. The FIEP Bulletin, v. 85, p. 393-395, 2014.

BAtAglion, G. A.; ZUChetto, A. T.; NASSER, J. P. Possibilidades e necessidades de crianças com deficiência na prática de atividades motoras. Revista Portuguesa de Ciências do Desporto, v. 3, p. 434-445, 2014. 
BRASIL. República Federativa do Brasil.. Disponível em: <http://www.planalto. gov.br/ccivil_03/constituicao/constituicaocompilado.htm> Acessado em 22 de maio de 2015.

DUARTE, R. Entrevistas em pesquisas qualitativas. Revista Educar, Curitiba, Editora UFPR, n. 24, p. 213-225, 2004.

FARIAS G. O. Carreira docente em Educação Física. 2010. Tese (Doutorado em Educação Física) - Universidade Federal de Santa Catarina, Florianópolis, 2010.

FARIAS, G. O.; NASCIMENTO, J. V. Construção da identidade profissional: metamorfoses na carreira docente em Educação Física. In: NASCIMENTO, J. V.; FARIAS, G. O. (Orgs.). Construção da identidade profissional em Educação Física: da formação à intervenção. Florianópolis: Editora da UDESC, 2012. p. 61-79.

FARIAS, G. O.; NASCIMENTO, J. V.; MOLETTA, A. F.; PINTO, M. G.; LIZ, C. C. A carreira docente na dimensão de ciclos ou estágios de desenvolvimento profissional. In: SOUZA, E. R.; NASCIMENTO, J. V.; AZEVEDO, E. S.; PEREIRA, B. O. (Orgs.). Educação Física, Lazer e Saúde: interfaces ao desenvolvimento humano. Florianópolis: Editora da UDESC, 2015. p. 225 - 250.

GONSALVES, E. P. Iniciação à Pesquisa Científica. Campinas: Alínea, 2007.

HUBERMAN, M. O ciclo de vida profissional dos professores. In: NÓVOA, A. (Org.) Vida de professores. Porto Alegre Editora, 1995. P.31-62.

HUNGER, D.; PEREIRA, J. M.; BORGES, C.; ROSSI, F. Conhecimentos para formação e intervenção em Educação Física: os desafios da docência universitária. In: NASCIMENTO, J. V.; FARIAS, G. O. (Orgs.). Construção da identidade 
profissional em Educação Física: da formação à intervenção. Florianópolis: Editora da UDESC, 2012. p. 373-395.

NOGUEIRA, M. D. P. Extensão universitária no Brasil: uma revisão conceitual. In: Farias DS, (organizador). Construção conceitual da extensão universitária na América Latina. Brasília (DF): Universidade de Brasília; 2001.

PETRICA, J. M.; SERRANO, J. J. A formação de profissionais de Educação Física: modelos de preparação para a prática. In: NASCIMENTO, J. V.; SOUZA, E. R.; RAMOS, V.; ROCHA, J. C. S. (Orgs.). Educação Física e Esporte: convergindo para novos caminhos. Florianópolis: Editora da UDESC, 2015. p. 295-306.

RIBEIRO, S. M. O esporte adaptado e a inclusão de alunos com deficiência nas aulas de Educação Física. 2009. Tese (Doutorado em Educação Física). Programa de Pós-Graduação UNIMEP. Piracicaba, SP, 2009.

SANTOS, N. Z.; BRACHT, V.; ALMEIDA, F. Q. Vida de Professores de Educação Física: o pessoal e o profissional no exercício da docência. Revista Movimento, Porto Alegre, v. 15, n. 02, p. 141-165, abril/junho de 2009.

SCHMITT, B. D.; ZUCHETTO, A. T. Engagement of a child with cerebral palsy in a Motor Activity Adapted Program. The FIEP Bulletin, v. 84, p. 389-392, 2014.

SCHMITT, B. D.; ZUCHETTO, A. T. Fatores que interferem na gestão do tempo em aulas de Educação Física Adaptada, na água, no contexto de ensino-formação. Revista Mineira de Educação Física (UFV), v. 03, p. 1025-1029, 2012.

SHERRILL, C. Adapted physical activity, recreation and sport crossdisciplinary and lifespan. Boston, MA: William C. Brown/McGraw Hill; 2004. 
SOUSA, A. L. L. A história da extensão universitária. $2^{\mathrm{a}}$ ed. Campinas, SP: Alínea, 2010.

TAVARES, D. M. S.; SIMÕES, A. L. A.; POGgetTO, M. T. D.; SILVA, S. R. Interface ensino, pesquisa, extensão nos cursos de graduação da saúde na Universidade Federal do Triângulo Mineiro. Revista Latino-am Enfermagem, v. 15, n. 6, nov./dez. 2007.

UFSC - Universidade Federal de Santa Catarina. < http://estrutura.ufsc.br> Acessado em 20 de maio de 2015.

WINNICK, J. P. Adapted physical education and sport. 5. ed. Champaign: Human Kinectics; 2011. 656p.

ZUCHETTO, A. T. A trajetória de Laila no AMA: Histórias entrelaçadas. 2008. Tese (Doutorado em Saúde da Criança e do Adolescente). Programa de PósGraduação Saúde da Criança e do Adolescente, Faculdade de Ciências Médicas. Unicamp, SP, 2008, f. 210

ZUCHETTO, A. T.; FRANÇA, C.; NASSER, J. P. Adequações, dificuldades e auxílios necessários para o engajamento de um autista em atividade motora. Revista Lecturas, Educación Física y Deportes, Buenos Aires. v. 16. n. 158, 2011. 


\title{
PERFORMANCE AND PROFESSIONAL DEVELOPMENT PHYSICAL EDUCATION STUDENTS ADAPTED OF GRADUATES OF DEGREE IN PHYSICAL EDUCATION OF FEDERAL UNIVERSITY OF SANTA CATARINA
}

\begin{abstract}
The objective was to analyze the experiences of seven former students of the Federal University of Santa Catarina who had scholarship (extension, monitoring, scientific research) of the Motor Activity Program Adapted, considering the teaching career development. Was used semi-structured interviews. It was categorized in the following professional development cycles: Input career, consolidation of professional skills and career statement and diversified career. Regarding the professional performance, it was found remained temporary abandonment and withdrawal in the field of Adapted Physical Education. It was observed the influence of the AMA in the professional practice of the participants, as reported this influence on their teaching behavior.
\end{abstract}

Keywords: Education continuing, Teacher, Physical Education.

\section{ACTUACIÓN Y DESARROLLO PROFESIONAL EN EDUCACIÓN FÍSICA ADAPTADA DE ALUMNOS EGRESADOS DEL CURSO DE LICENCIATURA EN EDUCACIÓN FÍSICA DE LA “UNIVERSIDAD FEDERAL DE SANTA CATARINA"}

Resumen: El objetivo fue analizar las experiencias vividas por siete alumnos egresados de la "Universidade Federal de Santa Catarina" que se desempeñaron como becarios (extensión, monitoría, iniciación científica) del programa de Actividad Motor Adaptada, considerando los ciclos de desarrollo de la carrera docente. Se utilizaron entrevistas con un guión semi-estructurado. Se clasificaron los siguientes ciclos de desarrollo profesional: ingreso a la carrera, afirmación y diversificación en la carrera. Desde el punto de vista de la actuación profesional se verificó la permanencia, el abandono temporario y la desistencia en el área de la Educación Física Adaptada. Se observó la influencia del AMA en la actuación profesional de los participantes, ya que relataron dicha influencia en su conducta docente.

Palabras clave: Educación contínua, Profesor, Educación Física. 